\title{
Motivating health professionals through control mechanisms: A review of empirical evidence
}

\author{
Pierluigi Smaldone , Milena Vainieri \\ Laboratorio Management e Sanità, Institute of Management, Scuola Superiore Sant'Anna of Pisa, Italy
}

Received: January 26, 2016

DOI: $10.5430 /$ jha.v5n3p67

\begin{abstract}
This paper summarizes the findings of the literature on the levers used in the health care sector to motivate workers, with a particular focus on the impact of management control tools (such as Performance Measurement Systems (PMS) and Pay for Performance) on motivation. A review of the literature was carried out using the ISI Web of Knowledge, Pubmed and JSTOR search engines on the topic of motivation of health care workers, including, if possible, all the involved categories of employees. The research focused on empirical studies published in Europe, North America and Oceania from 1990 to 2015. Developing countries were intentionally excluded because of their specific needs and motivation perspectives that mainly focus on recruitment or retention strategies to ensure services provision. Studies on motivation generally focus on three main perspectives: (1) Employees' satisfaction and emotions; (2) Retention; (3) Motivation or attitudes to carry out specific tasks or to behave appropriately. A few studies considered compensation strategies and monetary rewards as a driver of health care workers' motivation. These studies did not report the crowding out effect of external locus of causality on motivation. On the contrary, most of the studies highlighted the importance of the relationship with patients and colleagues as a crucial factor affecting workers' motivation, in particular referring to job satisfaction. Despite the large number of articles on the topic of employee motivation, there have been very few studies on the impact of the most popular managerial mechanisms introduced since the mid 1990s in health care systems.
\end{abstract}

Key Words: Motivation, Health care, Personnel

\section{INTRODUCTION}

Organizational performance has been usually seen as critically dependent on employee motivation, with service quality, efficiency, and equity, all directly mediated by the willingness of employees to apply themselves to their tasks. Indeed, since the mid 1990s, both scholars and practitioners have been promoting managerial tools to orient individuals and organizations. In particular, on the way of New Public Management, there has been a growing recourse to private tools in the public sector. These can be divided into two main groups: performance measurement systems (PMS) ${ }^{[1]}$ and compensation plans (i.e. P4P). ${ }^{[2-4]}$ Among the different managerial strategies, health care organizations and systems have concentrated their efforts on performance measurement tools. Goals (as well as PMS) affect performance because they direct attention, mobilize effort, enhance persistence, and motivate strategy development. Therefore, goal setting contributes to improve task performance when goals appear specific and sufficiently challenging. ${ }^{[4]}$ Employees feel more satisfied and involved in their activities when the goals are

\footnotetext{
*Correspondence: Pierluigi Smaldone; Email: pierluigismaldone@gmail.com, p.smaldone@ sssup.it; Address: Laboratorio Management e Sanità, Institute of Management, Scuola Superiore Sant'Anna of Pisa, Piazza Martiri della Libertà 33, 56127, Pisa, Italy.
} 
sufficiently clear and thoroughly defined. Therefore, goal setting is one of the most influential tools used by managers have to motivate their workers.

At present, there is an ongoing debate on the role of financial incentives. Unfortunately, different and sometimes contrasting evidence of the influence of financial incentives on workers' motivation is available. On the one hand, money is sometimes seen as a physicians' priority, ${ }^{[5]}$ while, on the other hand, financial incentives are associated with negative effects or with intrinsic motivation reduction after extrinsic motivation elicitation. ${ }^{[6-8]}$ Policy makers have often relied primarily on financial incentives. There is, however, even if there is substantial debate on the prospects for and effectiveness of performance-related pay in public sector contexts. ${ }^{[9]}$ Even when financial incentives are not explicitly used to promote higher productivity, the underlying philosophy of many health sector reform programs often implies that money is a key motivator in the work context. ${ }^{[10]}$ Nevertheless, it seems clear that financial incentives alone can't resolve motivation problems, although they should be factors that decisively influence workers motivation. Scholars and practitioners should keep in mind that it is scientifically impossible to draw univocal conclusions about the positive or negative effect of the financial lever on both motivation and performance. As a matter of fact, managerial strategies purely founded on financial incentives could also exercise unfavorable effect on staff motivation. ${ }^{[6]}$ Rather, the prospect of reaching monetary rewards could be perilously placed before the achievement of organizational goals in health care or, in general, public service provision. ${ }^{[11]}$ For this reason, workers could overestimate financial rewards compared to other types of reward. The literature sometimes shows differences in the implementation of financial incentives for different professionals. For example, general practitioners do not feel a decrease in their internal motivation, while nurses do. ${ }^{[12]}$ Academic debate about the supposed tradeoff between extrinsic rewards, such as financial incentives, and motivation, has been heated in the past decade. ${ }^{[13,14]}$

Some authors have highlighted the crucial influence of nonmonetary factors on motivation, such as reputation or learning. ${ }^{[15,16]}$ Resource availability and worker competence are necessary but not sufficient to ensure desired organizational performance. ${ }^{[10]}$ Franco et al.'s conceptual framework considers several motivational factors operating at the individual level in health care workers. These factors are divided into two main groups: the extent to which workers adopt organizational goals ("will do") and the extent to which workers effectively mobilize their personal resources to achieve joint goals ("can do"). According to their origins, determinants can be based at the individual level, at the immediate orga- nizational context level, and at the cultural context level. Hence, Franco et al. itemize individual level determinants, such as individual goals, self-concept, expectations, and experience of outcomes, in turn coupled with worker's technical and intellectual ability to perform and with the physical available resources. By focusing on the organizational context, they also consider organizational structures, resources, processes, and culture, as well as organizational feedback on performance, as contributing to the individual motivational processes. Finally they take into account cultural and community influences, through two main dimensions: the relationship between organizational functioning and societal culture, and the effect of the interactions and links with assisted patients on professionals' behavior. The conceptual model has also clarified how health sector reform can positively affect worker motivation. Health sector policy makers can operate in order to implement goal congruence (workers/organizations relationships) and improve worker motivation by considering the following in the policy design process: addressing multiple channels for worker motivation, recognizing communication and leadership importance, identifying both cultural and organizational values to facilitate or impede reforms, and understanding that reforms may have differential impacts on various health workers settings.

This paper summarizes the findings of the literature on the levers applied to the health care sector to motivate workers with a particular focus on the impact of management control tools (such as Performance Measurement System) ${ }^{[17]}$ on motivation. Both internal and external drivers are examined in order to highlight their effects on motivation. This is defined considering its possible meanings and nature, such as workers job satisfaction level, retention strategies success, turnover dynamics. On the basis of previous research, we were able to focus on retention as a sign of organizational attractiveness and individual fulfillment. Thus organizations able to retain their workers longer de facto reveal their capability to motivate them to the permanence. In a few words, motivated and satisfied personnel is clearly less inclined to leave the current job.

As shown in Figure 1, the factors influencing motivation can be divided into two main groups: the so called control mechanisms ${ }^{[18,19]}$ and the other mechanisms that are usually analyzed by social and psychological disciplines (e.g. Human Resource Management [HRM]) such as job design, interpersonal relationships, team work features. ${ }^{[20-22]} \mathrm{Mo-}$ tivation in turn exercises its influence on both individual and organizational performance. In addition to this main motivation-centered flow, there are other endogenous and exogenous factors which act as moderators, affecting the strength of the relation between the variables considered. 
These factors influence, on the one hand, the relationship between control mechanisms and other mechanisms with motivation; on the other hand, the relationship between motivation and performance. Hence, this review aims at answering to the following research question: what is the impact of control mechanisms on motivation?

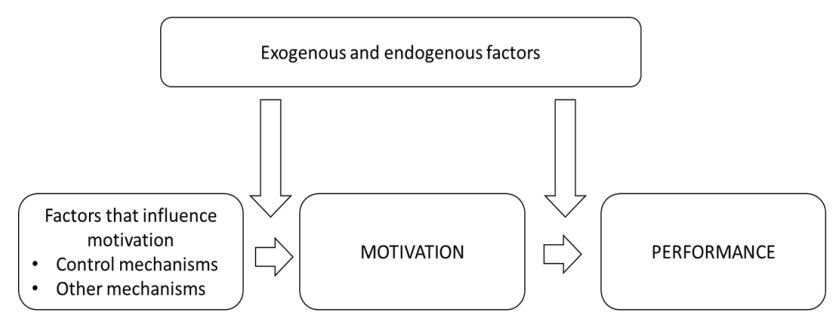

Figure 1. Relationships between operational mechanism, motivation and performance

\section{FRAMEWORK}

Our literature review is mainly based on Flamholtz et al. "integrative framework of organizational control". It allows us to recreate the process in figure 1. Moreover, the framework focuses on both individual and organizational perspectives; it illustrates the relationship between drivers, motivation and performance. Indeed, by considering factors affecting motivation, it highlights the difference between control mechanisms, ${ }^{[18,19]}$ directly regulated by managers, and other mechanisms usually analyzed by social and psychological disciplines (e.g. HRM) such as job design, interpersonal relationships and team work features. ${ }^{[20-22]}$ The original model is based on four core control mechanisms (planning, measurement and information process, feedback, evaluation reward) that seek to influence the behavior of individuals within the organization. They constitute the so-called core control system that interacts with the other operational subsystem and outcome element of the organization. The above-mentioned core control system is embedded in a wider control context. It involves external elements on which managerial tools can't directly exercise their influence. The core control system is influenced by the control context: external environment, the organizational culture and structure. The control context can facilitate or inhibit the effectiveness of the core control system in coordinating human efforts toward the attainment of organizational goals. "It may facilitate control effectiveness by the additional control that is imparted by several dimensions in the various contextual factors". ${ }^{[18]}$ Therefore, according to the perspective of our review, the control mechanism can be identified as the core element of the model.

Published by Sciedu Press

\subsection{Drivers affecting motivation and, in turn, perfor- mance}

In order to answer the research question our analysis refers to the cybernetic process of goal and standard setting, measurement and comparison, evaluation and feedback for corrective actions. ${ }^{[23]}$ Hence our review specifically focuses on four core control mechanisms: planning, measurement, feedback and evaluation reward elements. First of all, planning involves the setting of work goals for each key functional area and the set of standards for each goal. It is an ex ante form of control because it produces the information needed to guide individual or collective behavior. This control mechanism is the main vehicle for promoting goal congruence between individuals and their organizations. ${ }^{[18]} \mathrm{Next}$, measurement and the management information system involves numbers assignment to objects according to rules, then it influences work behavior with the information produced as well as with process of measurement. ${ }^{[24]}$ The element considered carries out an important twofold task: on the one hand, its informational function is a form of ex post control, and, on the other hand, its behavioral or process function may be considered an ex ante control. The feedback element refers to the information provided on employees behavior and work outcomes. Feedback can control the work behavior of organizational members either in a directional or motivational way. Therefore, feedback directs behavior by providing the information needed for corrective action and, at the same time, it motivates by serving as a promise for future rewards. ${ }^{[25,26]}$ The evaluation-reward element involves the assessment of individual or collective performance against pre-established goals and standards, based upon the information gathered and shown by the measurement system and the personal observation of managers. It represents a form of ex post control. Rewards are outcomes of behavior which are desirable to a person and which can be either extrinsic or intrinsic. ${ }^{[18]}$

\subsection{Motivation}

Motivation is usually related to the job satisfaction of an employee. ${ }^{[27,28]}$ It has been identified by several perspectives and meanings. It can be broadly defined as the willingness to exert different degrees of effort towards achieving organizational goals and satisfying existing needs. ${ }^{[1]}$ Moreover it represents a key factor for the performance of individuals and organizations, ${ }^{[29]}$ so that it is unanimously analyzed as an important variable to be profitably adopted by health care managers. Besides, it is often weighted out through retention strategies success, including its various displays, such as intention to quit, intention to stay, recruitment, turnover, absenteeism. Indeed, previous studies have considered motivation as a significant predictor of intention to quit workplace. ${ }^{[30,31]}$ Hence, in this review, motivation has been defined as: job 
satisfaction, retention, and work attitude. In particular, work attitude was defined by Flamholtz (e.g. commitment, alienation) as an outcome element constituent.

In this paper, motivation has been identified and defined by merging two different approaches: (1) Flamholtz et al.'s integrative framework of organizational control which considers motivation as an outcome; (2) The job characteristic model $^{[22]}$ measures motivation through job satisfaction, absenteeism, work motivation and performance, in turn, influenced by critical psychological states affected by five job characteristics (i.e. skill variety, task significance, feedback... ) impact. The two above-mentioned models include, in the outcome element, performance (e.g. sales volume, productivity, profit margin), motivation (e.g. satisfaction, commitment, work attitude), turnover and absenteeism. Nevertheless, we have concentrated on the motivation item.

\section{Methodology}

The review was carried out using the ISI Web of Knowledge, Pubmed and JSTOR search engines on the topic of health care employee motivation. Articles written (in English) from 1990 to 2015 were searched, in order to find almost all current empirical studies published in Europe, North America and Oceania. Developing countries were intentionally excluded because of their specific needs and motivation perspectives which mainly focus on recruitment or retention strategies in order to ensure services provision. Only empirical studies were selected while previous literature reviews and positional papers were excluded. Our research algorithm also comprised several kinds of health care or assistance organizations, such as hospitals, university hospitals and nursing homes. We refined our set of retrieved articles by following these three main steps: (1) title; (2) abstract; (3) full text reading.

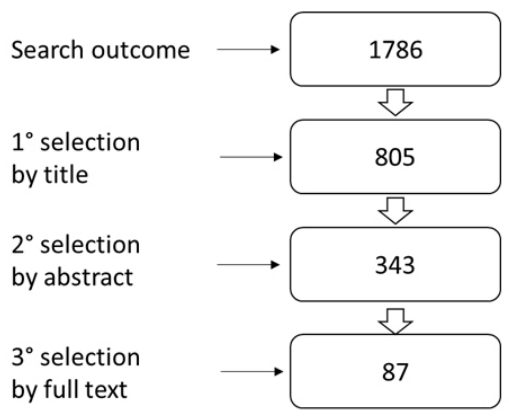

Figure 2. The selection process for the review

We first refined a 1,786 set of articles. In the first step, we obtained 805 articles by using titles as refinement factor. In the second step 343 articles were selected to be read. Finally, in the third step, 87 articles were obtained. We examined the definitive set of articles to draw useful inferences and subsequently some conclusions from different points of view. The results were grouped considering the previously mentioned drivers (see Figure 2).

\section{RESULTS AND DISCUSSION}

According to the geographical distribution of the papers, it is possible to observe that the papers considered are almost equally distributed between Europe and North America. Indeed, forty articles focus on North America and thirty-four on Europe. Three papers are from Oceania and only one from Israel. Four studies compare systems or organizations located within different countries. This selection allowed us to draw some preliminary considerations on health care worker categories which are generally involved in studies dealing with motivation: nurses and then physicians are the most analyzed professionals. A few studies focus on specialists, such as anesthetists, cardiologists or academic staff and only four of them concern general practitioners and primary care physicians. ${ }^{[32-35]}$ From a general perspective, the majority of the articles deals with the relationship between the operational subsystem (managers behaviour and leadership styles, contacts between colleagues, relationships with patients, etc...) and the professionals' satisfaction. On the contrary, only a few studies consider compensation strategies and monetary rewards as very crucial drivers. In addition, very few studies analyzed the effect of the relationship between both control context and core control system variables on performance.

As shown in Figure 3, many studies (sixty-three) explain how control context factors (external environment; organizational culture; organizational structure) may influence motivation. These studies are in whole or in part focused on contextual factors together with control mechanisms or on their own. Sixty-four studies consider the relationship between motivation and operational subsystem elements (i.e. interpersonal relationship, leadership style, teamwork). Within the core control system, eighteen studies explain the planning process influence on motivation, positively associated to goal standards identification. Moreover, nine studies are based on evaluation and, above all, on the reward system as a managerial choice to inspire personnel. Lastly, nine papers deal with the measurement and information process and two of them consider feedback to enhance motivation of health care workers. As above mentioned, in this review we focused on findings related to the four control mechanisms. The majority of the studies, included into the review, focus on two or more control mechanisms. At the same time, the studies often consider the influences exerted by both control mechanisms and different factors (i.e. external environment, operational 
subsystem, personal relationships, etc...). Some inferences are drawn, at a later step to understand the correlations between control mechanisms and motivation measures, taking into account the influences exercised by internal and external factors operating as moderators.

63 Control context (External environment; Organizational culture; Organizational structure)

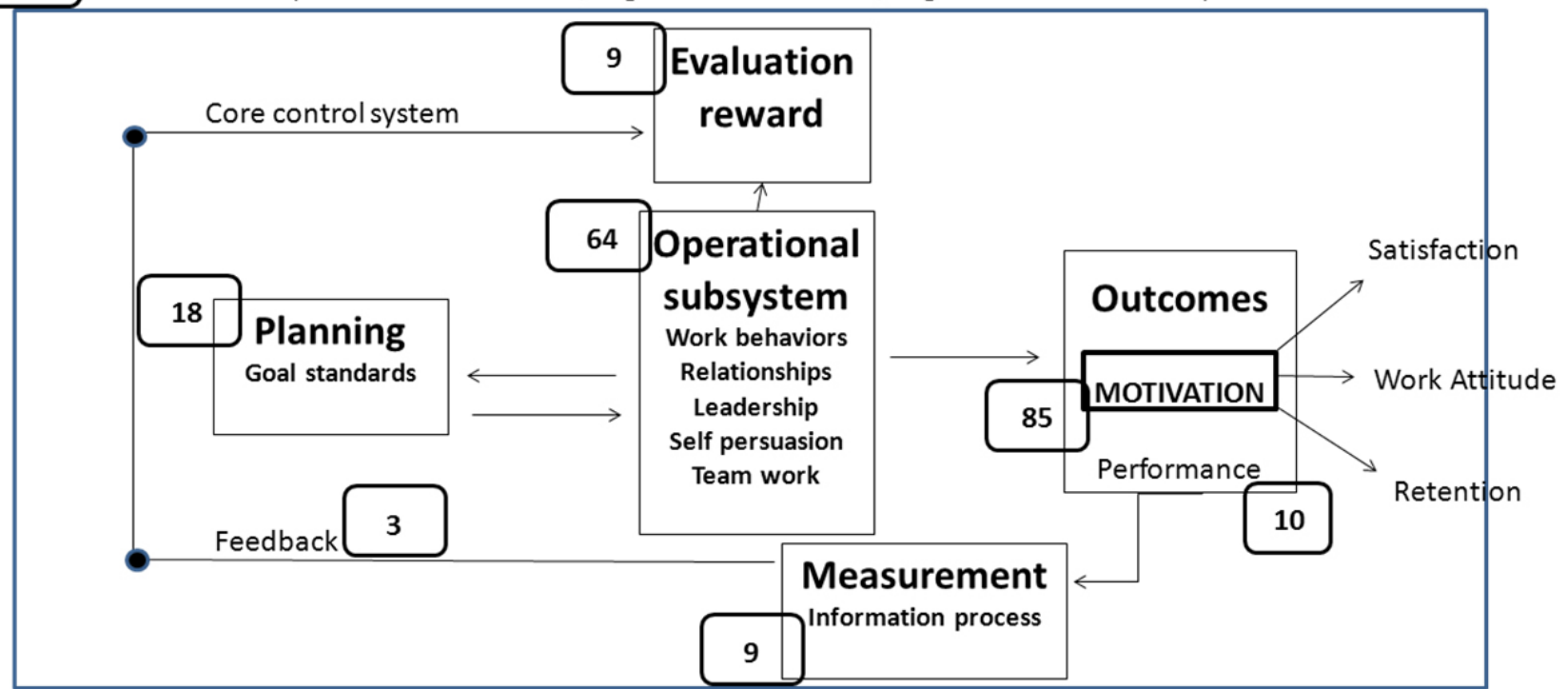

Figure 3. Results within the framework adapted from Flamholtz et al. ${ }^{[18]}$

\subsection{Planning and motivation}

At the end of the review process, we noted that eighteen articles consider the effects of planning elements on motivation through goal standard settings. Planning elements are fundamentally associated with motivation to be interpreted both as job satisfaction (thirteen studies) and retention (six studies). The influence of this mechanism on motivation is mainly presented by scholars as moderated by internal factors. Connolly et al. ${ }^{[36]}$ for example, consider the training on tools embedded within organizational plans, motivation to use this tool and the workers outcome expectancy. They found a positive effect of expectations on motivation as well as Papadatou et al. ${ }^{[37]}$ Other effects can be exercised on organizational and professional withdrawal intent. For instance, the reduction time to plan is associated with an increase in long-term sick leave, and a negative effect on retention strategies success. ${ }^{[38]}$ Conversely, a positive impact of job content clarity, jointly with team structure and job design, on employee well-being measured as job satisfaction and job stress has been observed. ${ }^{[20]}$ Goals determination and clarity of duties (considered among job attributes such as authority, creativity opportunities, job control or decision-making) can be assumed as motivators too. ${ }^{[39]}$ Finally, organizational goals and values harmony together with professionals' attitude can be considered crucial factors affecting job satisfaction as well as recruitment and retention. ${ }^{[40]}$ Moreover, professionals au- tonomy and independence seem to positively influence their turnover intentions and responsibility feelings. Hence, these factors should be carefully contemplated by managerial planners. For instance, the use of self-scheduling (considering also the ability of staff members to choose the day and shift of work) could increase retention degree, following predetermined criteria that ensures appropriate unit staffing. ${ }^{[41]}$ Goal clearness and downsizing process seems to be crucially relevant too. Focusing on Norwegian employed nurses, Røed $\&$ Fevang highlighted relevant repercussions on the level of sickness absence and professionals well-being. ${ }^{[42]}$

Studies focusing on organizational context were included within this section. Among the eighteen articles demonstrating a correlation between the planning factor and motivation, eleven consider the influence exercised by other factors such as the work-force and laboratory reduction or the shifts of personnel. All these elements are clearly under managerial control, aimed at promoting goal congruence between the individuals and their organizations.

\subsection{Evaluation-rewards and motivation}

Nine articles deal with the evaluation-reward element (i.e. merit pay) whose effect on satisfaction should be higher for older employees than for younger ones. ${ }^{[3]}$ Seven articles mainly focus on motivation, measured as job satisfaction, while three studies also considered retention. Financial in- 
centives seem to be only one of the several factors influencing both motivation and quantity decisions in service provision. These studies do not find a negative effect on motivation. ${ }^{[39-43]}$ Concerning evaluation and reward element analysis, it turns out that health care worker satisfaction and retention are positively influenced by rewards. Lambrou et al. ${ }^{[39]}$ presented a main motivators rank: remuneration seems to be at the second place, after achievement factors (job meaningfulness, interpersonal relationships, etc...). The other motivators are co-worker elements referring to the relational work environment, while job attributes are placed last. Lambrou et al., at the same time, have highlighted that the remuneration factor would have been more influential with female doctors and nurses and with accident or emergency outpatient doctors. Another evidence on financial incentives relates to teaching activities: financial compensation is studied as only one of the several factors motivating preceptors in teaching activities; however the powerful level is the high value preceptors have on intrinsic reasons (i.e. they enjoy teaching) rather than extrinsic rewards. ${ }^{[44]}$

Temple et al.,${ }^{[45]}$ focusing on nursing assistants working in American nursing homes, highlight the important role played by compensation among several factors influencing turnover intentions. Specifically, the provision of competitive wages and benefits (particularly health insurance) and involvement of nursing assistants in resident care planning could potentially reduce their turnover, as it could maintain high levels of nurse staffing.

Moreover, payment models can somehow affect employee behavior and professional choices (especially general practitioners). Some authors maintain that physicians working in fee-for-service financed organizations are encouraged to overserve patients. On the contrary, patients seem to be underserved in the capitation payment system. Nevertheless, financial incentives aren't the only motivators for physicians' quantity decisions, grounded on patient benefit. ${ }^{[43]}$ Furthermore, the job satisfaction level is lower for those paid according to a third party payer's fee-for-service schedule. ${ }^{[35]}$ If we focus on the relationship between reward element and the success rate of retention strategies, the remuneration level seems to be the key reason for leaving a location. Meanwhile, for others it is the "last straw" if they had feelings about the deficiency of their work environment. ${ }^{[46]}$ Finally, external events or exogenous factors within the control context, influence workers motivation according to different perspectives. Mathews et al. ${ }^{[46]}$ found out that older generation physicians, although limited in number, are sensible to the institutional and cultural context. Hence, they are pushed to leave in response to political events and policies.

\subsection{Measurement-information system and motivation}

Measurement-information processes are discussed in nine papers and all of them focused on motivation to be interpreted as employee satisfaction. A positive association between the measured monitoring factor and organizational performance was found. The measurement tool is mostly considered together with feedback-seeking promotion and, clearly, with reward strategy as its natural consequence. Moreover, the studies included within this section usually seemed to be unresponsive to the control context, which is more importantly concentrated on internal dynamics. Evidence of a positive influence of external practice monitoring and feedback-seeking promotion on motivation by supervisors was found. ${ }^{[47]}$ The management information system and role specification factor greatly influence professionals' satisfaction. In addition, evidence of a positive correlation with the measured collaboration value between pharmacists and physicians has been found. ${ }^{[48]}$ Supervisors or managers support and ex post control, as well as perceived distributive justice, positively influence employee satisfaction, especially in nurses. ${ }^{[49]}$ Interpersonal communications and employer-provided support programs are also found to be protective against nurses' job dissatisfaction. ${ }^{[50]}$ The importance of communication between physicians and managed care organizations is illustrated in the strong relationships between communication variables (problem reporting) and managed care decisions. Communication variables, in particular, have been measured thanks to the evaluation of problem reporting. ${ }^{[51,52]}$ However, employees' perception of communication and organizational culture seem to be decisively influential on several kind of outcomes, such as job satisfaction, commitment, occupational alienation, perceptions of patient care). ${ }^{[53]}$ More than anything else, the strong influence of practice monitoring on job satisfaction has been demonstrated mostly in organizations where practice is monitored by someone else. ${ }^{[51]}$

\subsection{Feedback and motivation}

Feedback and its promotion by supervisors seemed to be significantly correlated with the motive to seek feedback for professional self-improvement in medical residents. The three articles considered the influence of feedback on job satisfaction. Besides one article stressed the influence exercised by other internal or external factors such as job design or the institutional characteristics of the health care organization. This control mechanism has been appreciated by the feedback-seeking measurement. Indeed, focusing on health professionals on training, feedback is actually essential to assure their professional development, together with the monitoring process and fruitful evaluation mechanisms. ${ }^{[4]}$ Professionals seems to be more satisfied and mostly reassured when they receive feedback about their work. ${ }^{[54]}$ At the same 
time, scope and role clarity play an important role, especially considering different professionals cooperation and team working dynamics. Performance-avoid goal orientation represents another important factor according to the feedback motivational perspective. It has been defined as the desire to avoid looking incompetent in front of colleagues and, above all, supervisors. ${ }^{[55]}$ Performance-avoid goal orientation turns out to be highly and consistently associated with concerns to ask for feedback. Moreover, it may hinder medical residents in their professional development. From a gender perspective, women significantly show more concern on egoprotection than the opposite sex. Within academic organizations, giving importance to their specific environment as control context, physician research involvement and jointly research funding level, play an important role in reaching job satisfaction. ${ }^{[56]}$ Broadly, when the academic affiliate is located within walking distance, there are significant effects on performance feedback, skill development opportunities and work and family balance.

\section{Conclusions AND limitations}

In conclusion, the first consideration coming from this review is that, even though there are many articles analysing the association between the operational subsystem, work environment and professionals' satisfaction, only few studies focus on the effects of motivation on performance considering the four core control systems. Indeed, in this last 25 years, the majority of empirical studies (64 on the 87 selected) have focused on the relationship between the operational subsystems, mainly linked to HRM and organizational labor, and employees' motivation. Hence, despite the great relevance of New Public Management reforms, that involved US as well as other western health care systems, few management scholars investigated the impact of management control mechanisms on employees' motivation. While there is a flourishing health care literature on the framework adopted and the results obtained by the introduction of new management tools, less interest has been put on the influence on these tools on motivation.

In particular, the majority of the articles dealing with the four core control mechanisms focus on planning strategies. Empirical evidence on this control mechanism highlights that there is a positive influence on the correct use of (long and annual) planning strategies with motivation: goals clarity has positive effect on job satisfaction while the reduction of time to plan is negatively associated with retention to stay. However, these studies also put on evidence the important mediating effect of internal factors such as the outcome expectation.

With regard to the argued topic of the impact of monetary Published by Sciedu Press incentives, the studies included into the evaluation reward mechanism, showed that compensation strategies and monetary rewards are very crucial drivers. No evidence on the so-called crowding out effect of financial rewards have been found. However, the majority of the studies suggest that intrinsic motivation play a decisive role as workers behaviours guide, somehow independently from adopted control mechanisms. In particular, many of the empirical studies of this section focus on the impact of financial incentives on retention to stay of health care professionals. Due to these results, is interesting that yet most of studies analysing reward system focus attention on monetary reward rather than on reputation or learning process. This kind of reward could be more important in the health care sector which is characterized by high professionalism. Although money should be still used as a factor influencing motivation, more evidence is needed to suggest how to combine this element with other levers (such as for instance the public disclosure).

Studies related to measurement mechanisms highlighted the importance of communication strategies. It is not sufficient to put in place measurement tools, these should be disclosed in the right way throughout the organization. Indeed, visual management tools are more and more spreading within the organizations to boost the beneficial cognitive effect of measurement tools. Finally, very few studies deal with feedback of the control mechanism process with motivation in the health care sector. In particular they refer to other forms of feedback and to the presence and relation of health care workers with supervisors.

In general, we find many studies based on employee motivation considered as the attitude to do something or to behave somehow, referring to a specific task or a peculiar conduct. However, we do not find crucial differences based on the selected geographical areas referring to analyzed control mechanisms or to considered levers belonging to operational subsystem group of factors.

Studies from the U.S. seem to be more focused on the retention element among possible motivation measures (about $30 \%$, compared to $20 \%$ in other geographical areas). This predominance could be due to the features of the American health system where services are largely provided by private actors and turnover dynamics are relevant. Hence, American scholars and practitioners are more interested in measuring and analyzing the retention control mechanism rather than motivation.

In this review we analysed the influence of several factors characterizing different kinds of health care or assistance organizations (hospitals, nursing homes, etc...) and employees' categories (nurses, physicians, aides, etc...). In depth 
analyses could focus on the differences across employees' categories or organizations (private $v s$. public) to highlight whether there is any relationship between specific control mechanism and the professional area of employees. Addi- tional analyses could be done considering papers written in different languages (not only in English) to detect strategies pursued by other countries with a non-western culture such as Asian, African and South.

\section{REFERENCES}

[1] Gruening G. Origin and theoretical basis of New Public Management.International public management journal. 2001; 4(1): 1-25. http://dx.doi.org/10.1016/S1096-7494(01)00041-1

[2] Petersen LA, Woodard LD, Urech T, et al. Does pay-for-performance improve the quality of health care?. Annals of internal medicine 2006; 145(4): 265-272. PMid: 16908917. http://dx.doi.org/1 0.7326/0003-4819-145-4-200608150-00006

[3] Scott KL, Shaw JD, Duffy MK. Merit pay raises and organizationbased self-esteem. Journal of Organizational Behavior. 2008; 29(7): 967-980. http://dx.doi.org/10.1002/job. 539

[4] Locke EA, Shaw KN, Saari LM, et al. Goal setting and task performance: 1969-1980. Psychological bulletin. 1981; 90(1): 125 http://dx.doi.org/10.1037/0033-2909.90.1.125

[5] Shortell SM, Kaluzny AD. Health care management: organization design and behavior ( $5^{\text {th }}$ ed.). Clifton Park, NY: Delmar Learning. Behavior; 2006.

[6] Woolhandler S, Ariely D, Himmelstein DU. Why pay for performance may be incompatible with quality improvement. BMJ. 2012; 345(7870): e5015. PMid: 22893567. http://dx.doi.org/10.11 36/bmj.e5015

[7] Frey BS. Not just for the money. Books. 1997.

[8] Frey BS, Jegen R. Motivation crowding theory: a survey of empirical evidence. Institute for Empirical Research in Economics, University of Zurich. 1999.

[9] Nunberg B, Nellis J. Civil service reform and the World Bank (No. 422). The World Bank. 1990.

[10] Franco LM, Bennett S, Kanfer R. Health sector reform and public sector health worker motivation: a conceptual framework. Social science \& medicine. 2002; 54(8): 1255-1266. http://dx. doi.o $\mathrm{rg} / 10.1016 / \mathrm{S} 0277-9536$ (01) 00094-6

[11] Giacomini M, Hurley J, Lomas J, et al. The Many Meanings of Money: A Health Policy Analysis Framework for Understanding Financial Incentives. Centre for Health Economics \& Policy Analysis Working Paper. 1996.

[12] McDonald R, Harrison S, Checkland K, et al. Impact of financial incentives on clinical autonomy and internal motivation in primary care: ethnographic study. BMJ. 2007; 334(7608): 1357. PMid: 17580318 http://dx.doi.org/10.1136/bmj.39238.890810.BE

[13] Perry JL, Hondeghem A, Wise LR. Revisiting the motivational bases of public service: Twenty years of research and an agenda for the future. Public administration review. 2010; 70(5): 681-690. http://dx.doi.org/10.1111/j.1540-6210.2010.02196.x

[14] Wright BE. Public service and motivation: Does mission matter? Public administration review. 2007; 67(1): 54-64. http://dx.doi . org $/ 10.1111 / j .1540-6210.2006 .00696 . x$

[15] Kolstad JR. How to make rural jobs more attractive to health workers. Findings from a discrete choice experiment in Tanzania. Health economics. 2011; 20(2): 196-211. PMid: 20094993. http://dx.doi.org/10.1002/hec.1581

[16] Hibbard JH, Stockard J, Tusler M. Does publicizing hospital performance stimulate quality improvement efforts? Health Affairs. 2003;
22(2): 84-94. PMid: 12674410. http://dx.doi.org/10.1377/h lthaff.22.2.84

[17] Nuti S. Il Sistema di valutazione della performance in sanità (Performance evaluation system in the healthcare sector). Bologna Il Mulino. 2008.

[18] Flamholtz EG, Das TK, Tsui AS. Toward an integrative framework of organizational control. Accounting, organizations and society. 1985; 10(1): 35-50. http://dx.doi.org/10.1016/0361-3682(85) 9 0030-3

[19] Ferreira A, Otley D. The design and use of performance management systems: An extended framework for analysis. Management accounting research. 2009; 20(4): 263-282. http://dx.doi.org/10.10 $16 / j$.mar. 2009. 07.003

[20] So TT, West MA, Dawson JF. Team-based working and employee well-being: A cross-cultural comparison of United Kingdom and Hong Kong health services. European journal of work and organizational psychology. 2011; 20(3): 305-325. http://dx.doi.org/1 $0.1080 / 13594320903384821$

[21] Savič BS, Robida A. Capacity of middle management in health-care organizations for working with people- the case of Slovenian hospitals. Human resources for health. 2013; 11(1): 18. PMid: 23663315. http://dx.doi.org/10.1186/1478-4491-11-18

[22] Hackman JR, Oldham GR. Motivation through the design of work: Test of a theory. Organizational behavior and human performance. 1976; 16(2): 250-279. http://dx.doi.org/10.1016/0030-507 3(76) $90016-7$

[23] Wiener N. The human use of human beings: Cybernetics and society (No. 320). Da Capo press. 1954.

[24] Flamholtz EG. Toward a Psycho-technical Systems Paradigm of Organizational Measurement*. Decision Sciences. 1979; 10(1): 71-84. ht tp://dx.doi.org/10.1111/j.1540-5915.1979.tb00008.x

[25] Annett J. Feedback and human behaviour : The effects of knowledge of results, incentives and reinforcement on learning and performance. Feedback and human behaviour: the effects of knowledge of results, incentives and reinforcement on learning and performance. Penguin. 1969.

[26] VandeWalle D, Ganesan S, Challagalla GN, et al. An integrated model of feedback-seeking behavior: disposition, context, and cognition. Journal of Applied Psychology. 2000; 85(6): 996. PMid: 11125662. http://dx.doi.org/10.1037/0021-9010.85.6.9 96

[27] Herzberg F. One more time: How do you motivate employees. New York: The Leader Manager; 1986. 433-448.

[28] Lawler III EE. Motivation in work organizations. 1973.

[29] Hornby P, Sidney E. Motivation and Health Systems Performance. 1988.

[30] Alihonou E, Soude T, Hounyé F. La motivation et la performance du personnel de santé au Bénin (Motivation and perforance of personnel within Bénin healthcare system). UNICEF. 1998.

[31] Hasselhorn HM, Tackenberg P, Peter R. Effort-reward imbalance among nurses in stable countries and in countries in transition. International Journal of Occupational And Environmental Health. 2004; 
10(4): 401-408. PMid: 15702754. http://dx.doi.org/10.1179 /oeh.2004.10.4.401

[32] Pathman DE, Steiner BD, Jones BD, et al. Preparing and retaining rural physicians through medical education. Academic Medicine. 1999; 74(7): 810-20. PMid: 10429591. http://dx.doi.org/10. 1097/00001888-199907000-00016

[33] Roberts A, Creech AH, Blue W. A multistate program to educate physicians: successful, economical, but endangered. Academic Medicine. 1995; 70(7): 578-82. PMid: 7612123. http://dx.doi . org/10.1097/00001888-199507000-00008

[34] Martínez-I-igo D, Totterdell P, Alcover CM, et al. The source of display rules and their effects on primary health care professionals' well-being. The Spanish journal of psychology. 2009; 12(02): 618-631. http://dx.doi.org/10.1017/S1138741600001980

[35] Warren MG, Weitz R, Kulis S. Physician satisfaction in a changing health care environment: the impact of challenges to professional autonomy, authority, and dominance. Journal of Health and Social Behavior. 1998; 356-367. PMid: 9919857. http://dx.doi.org/1 $0.2307 / 2676344$

[36] Connolly M, Thomas JM, Orford JA, et al. The impact of the SAGE \& THYME foundation level workshop on factors influencing communication skills in health care professionals. Journal of Continuing Education in the Health Professions. 2014; 34(1): 37-46. PMid: 24648362. http://dx.doi.org/10.1002/chp. 21214

[37] Papadatou D, Anagnostopoulos F, Monos D. Factors contributing to the development of burnout in oncology nursing. British journal of medical psychology. 1994; 67(2): 187-199. PMid: 7918213. http: //dx.doi.org/10.1111/j.2044-8341.1994.tb01785.x

[38] etterson IL, Hertting A, Hagberg L, et al. Are trends in work and health conditions interrelated? A study of Swedish hospital employees in the 1990s. Journal of occupational health psychology. 2005; 10(2): 110. PMid: 15826222. http://dx.doi.org/10.1037/107 $6-8998 \cdot 10 \cdot 2 \cdot 110$

[39] Lambrou P, Kontodimopoulos N, Niakas D. Motivation and job satisfaction among medical and nursing staff in a Cyprus public general hospital. Hum Resour Health. 2010; 8(1): 26-34. PMid: 21080954. http://dx.doi.org/10.1186/1478-4491-8-26

[40] Cross V, Hicks C, Parle J, et al. Perceptions of the learning environment in higher specialist training of doctors: implications for recruitment and retention. Medical education. 2006; 40(2): 121-128. PMid: 16451239. http://dx.doi.org/10.1111/j.1365-2929. 2005.02382.x

[41] Bluett L. Self-scheduling: Facilitate, don't control. Nursing management. 2008; 39(6): 12-14. http://dx.doi.org/10.1097/01.nu ma. 0000320632.43318 .42

[42] Røed K, Fevang E. Organizational change, absenteeism, and welfare dependency. Journal of Human Resources. 2007; 42(1): 156-193. http://dx.doi.org/10.3368/jhr.XLII.1.156

[43] Hennig-Schmidt H, Selten R, Wiesen D. How payment systems affect physicians' provision behaviour - an experimental investigation. Journal of Health Economics. 2011; 30(4): 637-646. PMid: 21683460. http://dx.doi.org/10.1016/j.jhealeco. 2011.05.001

[44] Latessa R, Beaty N, Landis S, et al. The satisfaction, motivation, and future of community preceptors: the North Carolina experi- ence. Academic Medicine. 2007; 82(7): 698-703. PMid: 17595570 http://dx.doi.org/10.1097/ACM. Ob013e318067483c

[45] Temple A, Dobbs D, Andel R. Exploring correlates of turnover among nursing assistants in the National Nursing Home Survey. Health Care Management Review. 2009; 34(2): 182-190. PMid: 19322049. http://dx.doi.org/10.1097/HMR.0b013e3 1819c8b11

[46] Mathews M, Seguin M, Chowdhury N, et al. A qualitative study of factors influencing different generations of Newfoundland and Saskatchewan trained physicians to leave a work location. Human resources for health. 2012; 10(1): 1-8. PMid: 22830486 http://dx.doi.org/10.1186/1478-4491-10-18

[47] Bose MM, Gijselaers WH. Why supervisors should promote feedback-seeking behaviour in medical residency. Medical teacher. 2013; 35(11): e1573-e1583.

[48] Zillich AJ, Doucette WR, Carter BL, et al. Development and initial validation of an instrument to measure physician-pharmacist collaboration from the physician perspective. Value in Health. 2005; 8(1): 59-66. PMid: 15841895. http://dx.doi.org/10.1111/j.152 4-4733.2005.03093.x

[49] Monroe J, DeLoach RJ. Job satisfaction: How do social workers fare with other interdisciplinary team members in hospice settings? OMEGA-Journal of Death and Dying. 2004; 49(4): 327-346. http://dx.doi .org/10.2190/J9FD-V6P8-GCMJ-HFE0

[50] Wilkins K, Shields M. Employer-provided support services and job dissatisfaction in Canadian registered nurses. Nursing Research. 2009; 58(4): 255-263. PMid: 19609177. http://dx.doi.org/10. 1097/NNR. 0b013e3181a308de

[51] Lammers JC, Duggan A. Bringing the physician back in: Communication predictors of physicians' satisfaction with managed care. Health Communication. 2002; 14(4): 493-513. PMid: 12375773. http://dx.doi.org/10.1207/S15327027HC1404_5

[52] Bergus GR, Randall CS, Winniford MD, et al. Job satisfaction and workplace characteristics of primary and specialty care physicians at a bimodal medical school. Academic Medicine. 2001; 76(11): 11481152. PMid: 11704519 . http://dx.doi .org/10.1097/0000188 8-200111000-00020

[53] Harber DG, Ashkanasy NM, Callan VJ. Implementing quality service in a public hospital setting: A path-analytic study of the organizational antecedents of employee perceptions and outcomes. Public Productivity \& Management Review. 1997; 13-29. http: //dx.doi.org/10.2307/3380531

[54] Conway J, Kearin M. The contribution of the Patient Support Assistant to direct patient care: An exploration of nursing and PSA role perceptions. Contemporary Nurse. 2007; 24(2): 175-188. PMid: 17563326. http://dx.doi.org/10.5172/conu.2007.2 4.2 .175

[55] VandeWalle D, Cummings LL. A test of the influence of goal orientation on the feedback-seeking process. Journal of applied psychology. 1997; 82(3): 390. PMid: 9190146. http://dx.doi.org/10.1037 10021-9010.82.3.390

[56] Mohr DC, Burgess Jr JF. Job characteristics and job satisfaction among physicians involved with research in the Veterans Health Administration. Academic Medicine. 2011; 86(8): 938-945. PMid: 21694559. http://dx.doi.org/10.1097/ACM.0b013e3 $182223 \mathrm{~b} 76$ 